Artikel Penelitian

\title{
Ekstraksi, Hidrolisis dan Partisi Metabolit Sekunder dari Mikroalga Chlorella sp.
}

\author{
Ahmad Ganaim Fasya*, Anike Riska Dinasti, Muharromatus Syofiyah, Laili Maghfiroh Rahmawati, Nuria \\ Millati, Dany Aulia Safitri, Singgih Handoko, Ahmad Hanapi, Rachmawati Ningsih \\ Jurusan Kimia, Fakultas Sains dan Teknologi, Universitas Islam Negeri Maulana Malik Ibrahim Malang, Indonesia
}

\section{INFO ARTIKEL}

Sejarah artikel

Submisi

Revisi

Diterima

Tersedia online: 1 Oktober 2016

Penulis Korespondensi

Email:

fasya.organik.uinmalang@gmail.com

\section{ABSTRAK}

Chlorella sp. contained some secondary metabolites, such as steroid compounds. The aim of this study is to get the secondary metabolites from Chlorella sp. based on solubility of the ethyl acetate and petroleum ether solvent. Chlorella sp. was cultivated in Tauge Extract Medium (TEM) $4 \%$ and was harvested on 10 days. Water content of sample was measured by thermogravimetric method. Extraction of microalgae, Chlorella sp., was conducted by maceration with methanol solvent and was followed by hydrolysis with $\mathrm{HCl} 2 \mathrm{~N}$. The result is partitioned with ethyl acetate and petroleum ether solvent. Yield percentage of extraction with methanol was $21.89 \%$. Hydrolysis and partition of microalgae Chlorella sp. using ethyl acetate and petroleum ether give yield percent $80.95 \%$ and $50.63 \%$, respectively.

Keywords: Chlorella sp., water content, maceration, hydrolysis, partition

\begin{abstract}
Mikroalga Chlorella sp. adalah tumbuhan tingkat rendah yang mengandung metabolit sekunder yaitu senyawa steroid. Penelitian ini bertujuan untuk mendapatkan senyawa metabolit sekunder yang terkandung dalam mikroalga Chlorella sp. berdasarkan kelarutannya terhadap pelarut etil asetat dan petroleum eter. Chlorella sp. dikultivasi dalam Media Ekstrak Tauge (MET) 4\% dan pemanenannya dilakukan pada hari ke-10. Biomassa hasil panen diukur kadar air dengan teknik termogravimetri dan dimaserasi menggunakan pelarut methanol. Ekstrak kasar hasil maserasi dihidrolisis dengan $\mathrm{HCl} 2 \mathrm{~N}$ dan dipartisi dengan masing-masing pelarut etil asetat dan petroleum eter. Hasil penelitian menunjukkan bahwa rendemen hasil ekstraksi pada pelarut metanol adalah $21,89 \%$. Rendemen hasil hidrolisis dan partisi adalah $80,95 \%$ untuk fraksi etil asetat dan $50,63 \%$ untuk fraksi petroleum eter.
\end{abstract}

Kata Kunci: Chlorella sp., kadar air, maserasi, hidrolisis, partisi

\section{Pendahuluan}

Chlorella sp. merupakan ganggang hijau bersel satu yang dapat hidup di air tawar, payau, dan asin. Beberapa keunggulan Chlorella sp. diantaranya berkembang biak dengan cepat dan mudah dalam membudidayaan (Sidabutar, 1999).
Masa adaptasi yang relatif singkat dan tahan terhadap kondisi lingkungan yang ideal bagi pertumbuhan Chlorella sp. menjadikannya mudah untuk dikultur.

Kultur Chlorella sp. dilakukan dalam Medium Ekstrak Tauge (MET) kacang hijau. MET 4\% 
mengandung komponen makro dan mikro nutrien yang dibutuhkan untuk pertumbuhan Chlorella sp. (Prihantini dkk., 2007). Selama proses kultivasi mikroalga Chlorella sp. mengalami empat fase pertumbuhan, yaitu fase log atau eksponensial, fase penurunan laju pertumbuhan, fase stasioner dan fase kematian. Pemanenan Chlorella sp. dilakukan pada hari ke-10 yang merupakan fase akhir stasioner dengan jumlah kelimpahan sel mikroalga Chlorella sp. tertinggi (Khamidah dkk., 2014).

Berbagai metode ekstraksi menawarkan banyak kemungkinan untuk hasil pemisahan. Salah satu metode ekstraksi yang digunakan dalam penelitian ini adalah maserasi. Proses ini menguntungkan untuk isolasi bahan alam yang bersifat tidak tahan terhadap suhu tinggi (Guenther, 1987). Senyawa metabolit sekunder yang lebih spesifik dapat diperoleh melalui proses hidrolisis dan partisi. Senyawa organik umumnya berbentuk glikosida yang terdiri dari glikon dan aglikon yang dihubungkan dengan ikatan glikosida. Senyawa metabolit sekunder tergolong dalam senyawa aglikon. Hidrolisis dilakukan dengan penambahan katalis asam untuk mempercepat reaksi pemutusan ikatan glikosida. Hasil hidrolisis dilakukan partisi untuk mengambil metabolit sekunder yang diinginkan yang mempunyai kesamaan kepolaran dengan pelarut.

\section{Bahan dan metode}

\subsection{Bahan}

Isolat mikroalga Chlorella sp. diperoleh dari Laboratorium Fisiologi Tumbuhan Jurusan Biologi Universitas Islam Negeri Maulana Malik Ibrahim Malang. Bahan-bahan yang digunakan adalah tauge kacang hijau, akuades, metanol (p.a), $\mathrm{HCl}$ $37 \%$, etil asetat (p.a), petroleum eter (p.a) dan natrium bikarbonat $\left(\mathrm{NaHCO}_{3}\right)$.

\subsection{Kultivasi mikroalga Chlorella sp.}

\subsubsection{Pembuatan medium ekstrak tauge $4 \%$}

Pembuatan Medium Esktrak Tauge (MET) 4\% diawali dengan melarutkan ekstrak tauge ke dalam akuades yang telah dibuat dengan konsentrasi $4 \%$ (Prihantini dkk., 2005). Ekstrak tauge dibuat dengan cara tauge kacang hijau sebanyak 100 gram yang telah dicuci bersih direbus dalam 500 $\mathrm{mL}$ akuades yang mendidih selama 1 jam. Ekstrak tauge diambil dan dimasukkan ke dalam erlenmeyer $1000 \mathrm{~mL}$ dan diencerkan hingga diperoleh MET dengan konsentrasi $4 \%$.

2.2.2. Kultivasi mikroalga Chlorella sp. dalam MET 4\% (Prihantini dkk., 2005)

Isolat Chlorella sp. sebanyak $10 \mathrm{~mL}$ diinokulasikan ke dalam masing-masing $60 \mathrm{~mL}$ MET 4\% dalam erlenmeyer dan ditempatkan pada rak yang dilengkapi dengan pencahayaan menggunakan lampu TL 36 watt (intensitas cahaya 1000 - 4000 lux) dan diinkubasi selama 10 hari dengan fotoperiodisitas 14 jam terang dan 10 jam gelap.

\subsubsection{Pemanenan biomassa Chlorella sp.}

Pemanenan biomassa Chlorella sp. dilakukan pada hari ke-10 dengan cara Chlorella sp. disentrifugasi dengan kecepatan 3000 rpm selama 15 menit. Endapan biomassa Chlorella sp. dipisahkan dari filtratnya kemudian dilakukan penimbangan yang dicatat sebagai berat basah (Desianti dkk., 2014).

\subsection{Preparasi sampel biomassa Chlorella sp.}

Biomassa Chlorella sp. dikeringanginkan selama 2 hari pada suhu ruang (berkisar antara 25 - $30^{\circ} \mathrm{C}$ ). Setelah diperoleh Chlorella sp. kering, dikerok dan ditimbang biomassa sebagai berat kering (Imamah dkk., 2015).

\subsection{Preparasi sampel biomassa Chlorella sp.}

Cawan yang akan digunakan dipanaskan dahulu dalam oven dengan suhu $100-105^{\circ} \mathrm{C}$ selama 15 menit. Selanjutnya, cawan disimpan dalam desikator selama 10 menit dan ditimbang. Prosedur tersebut diulang hingga diperoleh berat cawan yang konstan. Biomassa Chlorella sp. ditimbang 0,5 gram dalam cawan dan dikeringkan di dalam oven suhu $100-105^{\circ} \mathrm{C}$ selama 30 menit. Kemudian, dimasukkan ke dalam desikator, ditimbang dan dioven sampai diperoleh berat konstan. Kadar air sampel biomassa Chlorella sp. dihitung menggunakan persamaan (1) (AOAC, 1984).

Kadar air $=\frac{(b-c)}{(b-a)} \times 100 \%$

Dimana, a adalah berat cawan kosong, $b$ adalah berat cawan ditambah sampel sebelum dikeringkan, dan $\mathrm{c}$ adalah berat cawan ditambah sampel setelah dikeringkan. 


\subsection{Ekstraksi mikroalga Chlorella sp.}

Biomassa Chlorella sp. kering sebanyak 30 gram dimasukkan ke dalam gelas kimia $500 \mathrm{~mL}$ dan ditambahkan $150 \mathrm{~mL}$ pelarut metanol dengan perbandingan 1:5 (b/v), kemudian ditutup dengan aluminium foil. Sampel dikocokan menggunakan shaker dengan kecepatan 120 rpm selama 5 jam pada suhu kamar. Selanjutnya, sampel disaring menggunakan corong buchner. Residu yang diperoleh dimaserasi kembali hingga 3 kali proses ekstraksi. Filtrat yang diperoleh dari 3 kali maserasi tersebut digabung menjadi satu dan diuapkan pelarutnya menggunakan rotary evaporator vacum hingga terbentuk ekstrak pekat Chlorella sp. (Imamah dkk., 2015). Ekstrak pekat yang diperoleh ditimbang kemudian dihitung nilai randemen menggunakan persamaan (2).

$\%$ Rendemen $=\frac{\text { Berat ekstrak }}{\text { Berat sampel }} \times 100 \%$

\subsection{Hidrolisis dan partisi ekstrak metanol mikroalga Chlorella sp.}

Ekstrak metanol sebanyak 2,5 gram dimasukkan ke dalam gelas kimia dan dihidrolisis dengan $5 \mathrm{~mL} \mathrm{HCl} 2 \mathrm{~N}$ sambil diaduk menggunakan magnetic stirrer hot plate selama 1 jam pada suhu ruang (Tensiska dkk., 2007). Hidrolisat yang diperoleh ditambahkan dengan natrium bikarbonat hingga $\mathrm{pH}$ netral. Selanjutnya, hidrolisat ditambahkan $12,5 \mathrm{~mL}$ pelarut etil asetat, dikocok dan didiamkan hingga terbentuk dua lapisan yaitu lapisan organik dan lapisan air. Masing-masing lapisan dipisahkan. Proses partisi dilakukan sebanyak 3 kali. Lapisan organik dipekatkan dengan dialiri dengan gas $\mathrm{N}_{2}$. Ekstrak pekat yang diperoleh ditimbang dan dihitung rendemennya menggunakan persamaan (2) (Imamah dkk., 2015).

\section{Hasil dan pembahasan}

\subsection{Kultivasi mikroalga Chlorella sp.}

Media kultur yang digunakan dalam penelitian ini adalah Medium Ekstrak Tauge (MET) 4\%. Kultivasi dilakukan pada hari ke 6-7. Pada hari tersebut merupakan fase eksponensial dimana Chlorella sp. mengalami pembelahan aktif karena tersedianya nutrien dan pencahayaan yang cukup baik sehingga proses pertumbuhannya maksimal (Khamidah dkk., 2014). Chlorella sp. dikultivasi dalam MET 4\% dan diinkubasi selama 10 hari dengan fotoperiodisitas pengaturan 14 jam terang dan 10 jam gelap yang dianalogikan sebagai pengganti sinar matahari dalam proses fotosintesis.

Hasil penelitian menunjukkan selama proses kultivasi, mikroalga Chlorella sp. mengalami perubahan warna inokulum dari warna hijau kekuningan hingga hijau pekat. Perubahan warna tersebut mengindikasikan terjadinya peningkatan kadar klorofil yang merupakan pigmen utama pada mikroalga Chlorella sp. (Imamah dkk., 2015). Selain itu, perubahan warna tersebut juga menunjukkan kerapatan sel yang menandakan terjadinya pemanfaatan nutrien yang terkandung dalam MET oleh sel-sel Chlorella sp. (Prihantini, dkk., 2005).

Tahap pemanenan dilakukan pada hari ke-10. Hari tersebut merupakan fase akhir stasioner pra kematian yang mempunyai jumlah kelimpahan sel tertinggi yaitu $4.880 .000 \mathrm{sel} / \mathrm{mL}$ (Khamidah dkk., 2014). Pemanenan bertujuan untuk memisahkan biomassa Chlorella sp. dari MET 4\% menggunakan sentrifuga. Filtrat yang diperoleh berwarna bening kekuningan dan supernatan berwarna hijau pekat yang merupakan biomassa mikroalga Chlorella sp.

\subsection{Preparasi sampel}

Preparasi sampel dilakukan dengan cara dikeringanginkan pada suhu ruang. Pengeringan tidak dilakukan menggunakan oven dan sinar matahari secara langsung karena umumnya senyawa metabolit sekunder tidak tahan terhadap panas. Hasil pengeringan Chlorella sp. berwarna hijau kehitaman dan menempel pada permukaan wadah. Sampel yang telah kering dikerok sehingga didapatkan sampel padatan berupa serbuk. Hasil biomassa dari proses pengeringan sebesar 32,64 gram. Rendemen yang diperoleh adalah 1,336\%.

\subsection{Analisis kadar air}

Analisis kadar air bertujuan untuk mengetahui kandungan air dalam Chlorella sp. Jumlah air yang terkandung dalam sampel dapat mempengaruhi proses ketahanan sampel saat proses penyimpanan. Selain itu, sampel dengan kadar air yang rendah dapat mencegah tumbuhnya mikroorganisme yang dapat mendegradasi senyawa aktif yang terkandung dalam Chlorella sp. (Hayati dkk., 2012). Kadar air Chlorella sp. yang diperoleh sebesar $10,48 \%$. Nilai tersebut berada di bawah kadar air maksimum yang disyaratkan agar proses ekstraksi dapat berjalan dengan lancar yaitu 11\% (Setyaningsih dkk., 2013). 


\subsection{Ekstraksi senyawa aktif Chlorella sp.}

Ekstraksi senyawa aktif dalam penelitian ini menggunakan metode maserasi dengan pelarut metanol. Selama proses perendaman terjadi proses difusi karena adanya perbedaan tekanan didalam dan di luar sel. Larutan dengan konsentrasi yang rendah akan terdesak keluar dan digantikan dengan pelarut dengan konsentrasi yang tinggi. Metanol masuk ke sel Chlorella sp. melewati dinding sel. Hal ini mengakibatkan sitoplasma di dalam sel akan keluar dan ikut terlarut dalam pelarut metanol. Proses maserasi dilakukan tiga kali pengulangan hingga filtrat yang diperoleh berubah warna dari hijau kehitaman menjadi hijau lebih terang. Ekstrak kasar Chlorella sp. yang diperoleh sebesar 6,568 gram dengan nilai rendemen $21,89 \%$.

\subsection{Hidrolisis dan partisi ekstrak kasar}

Hidrolisis dilakukan untuk memutus ikatan glikosida menjadi senyawa glikon dan aglikon. Katalis yang digunakan berupa $\mathrm{HCl} 2 \mathrm{~N}$ untuk mempercepat reaksi hidrolisis. $\mathrm{HCl}$ merupakan asam kuat yang mudah melepaskan ion $\mathrm{H}^{+}$secara sempurna dalam air. Semakin banyak proton $\mathrm{H}^{+}$ yang dilepas, semakin mudah melepaskan ikatan glikosida (Handoko, 2006). Penambahan $\mathrm{HCl}$ akan terbentuk suasana asam yang akan dinetralkan dengan $\mathrm{NaHCO}_{3}$. Penetralan ini berfungsi untuk menghentikan reaksi hidrolisis yang bersifat reversibel. Apabila reaksi ini tidak dihentikan dengan cepat maka ikatan glikosida antara glikon dan aglikon yang terurai dalam proses hidrolisis dapat terbentuk kembali. Reaksi tersebut akan menghasilkan produk samping yang tidak berbahaya yaitu berupa garam $\mathrm{NaCl}$.

Hidrolisat yang diperoleh dilakukan partisi menggunakan variasi pelarut berupa etil asetat dan petroleum eter. Penggunaan pelarut yang berbeda ini dimaksudkan agar senyawa aktif yang memiliki kepolaran berbeda akan terekstrak kedalam pelarut yang sesuai. Hasil proses partisi membentuk dua lapisan yaitu fasa organik (lapisan atas) dan fasa air (lapisan bawah). Fasa organik mengekstrak senyawa aglikon yang mengandung metabolit sekunder dan fasa air mengekstrak komponen gula (glikon).
Tabel 1

Hasil rendemen fraksi hasil partisi Chlorella sp.

\begin{tabular}{llc}
\hline \multicolumn{1}{c}{ Filtrat } & Warna filtrat & $\begin{array}{c}\text { Rendemen } \\
\% \text { (b/b) }\end{array}$ \\
\hline Etil asetat & Hijau Kehitaman & 80,95 \\
Petroleum Eter & Hijau Kehitaman & 50,63 \\
\hline
\end{tabular}

Rendemen yang dihasilkan dari variasi kedua pelarut memiliki hasil yang berbeda. Pelarut etil asetat memiliki rendemen tertinggi yaitu $80,95 \%$. Hasil rendemen masing-masing fraksi memberikan informasi bahwa sebagian besar metabolit sekunder lebih terekstrak ke dalam pelarut etil asetat dibandingkan dengan petroleum eter.

\section{Kesimpulan}

Ekstraksi metabolit sekunder Chlorella sp. secara maserasi menggunakan pelarut metanol menghasilkan rendemen $21,89 \%$. Rendemen yang diperoleh dari proses hidolisis dan partisi dengan etil asetat dan petroleum eter berturut-turut yaitu $80,95 \%$ dan $50,63 \%$. Fraksi etil asetat menunjukkan jumlah rendemen yang lebih tinggi dibandingkan dengan fraksi petroleum eter.

\section{Daftar Pustaka}

AOAC. (1984). Official methods of analysis of the association of official analytical chemistry. Washington D.C: Association of Official Analytical.

Desianti, N., Fasya, A.G., \& Adi, T.K. (2014). Uji toksisitas dan identifiaksi golongan senyawa aktif fraksi etil asetat, kloroform, petroleum eter, dan n-heksana hasil hidrolisis ekstrak metanol mikroalga Chlorella sp. Skripsi, Universitas Islam Negeri Maulana Malik Ibrahim Malang, Kimia.

Guenther, E. (1987). Minyak Atsiri Jilid I. (K. S, Trans.) Jakarta: UI Press.

Handoko, D. S. (2006). Kinetika hidrolisis maltosa pada variasi suhu dan jenis asam sebagai katalis. SIGMA: Jurnal Sains dan Teknologi, 9(1). 
Hayati, E.K., Jannah, A., \& Ningsih, R. (2012). Identifikasi senyawa dan aktivitas antimalaria in vivo ekstrak etil asetat tanaman anting-anting (Acalypha indica, L.). Molekul, 7(1), 20-32.

Imamah, N., Fasya, A.G., Nasichuddin, A., \& Adi, K.A. (2015). Pemisahan senyawa steroid fraksi etil asetat hasil hidrolisis ekstrak metanol mikroalga Chlorella sp. menggunakan kromatografi lapis tipis (KLT) dan identifikasinya menggunakan spektrofotometer FTIR. Skripsi, Universitas Islam Negeri Maulana Malik Malang, Kimia. Khamidah, U., Fasya, A.G., \& Romaidi. (2014). Uji aktivitas antibakteri ekstrak metanol mikroalga Chlorella sp. pada fase stationer hasil kultivasi dalam medium ekstrak tauge (MET). ALCHEMY: Journal of Chemistry, 3(1), 1-7.

Prihantini, N.B., Damayanti, D., \& Yuniati, R. (2007). Pengaruh konsentrasi medium ekstrak tauge (MET) terhadap pertumbuhan Scenedesmus isolat Subang. MAKARA, SAINS, 11(1), 1-9.

Prihantini, N.B., Putri, B., \& Yuniati, R. (2005). Pertumbuhan Chlorella spp. dalam medium ekstrak tauge (MET) dengan variasi $\mathrm{pH}$ awal. MAKARA, SAINS, 9(1), 16.
Setyaningsih, D., Nurmillah, O.Y., \& Windarwati, S. (2013). Kajian aktivitas antioksidan dan antimikroba ekstrak biji, kulit buah, batan dan daun tanaman jarak pagar (Jatropha cucas, L.). Institiut Pertanian Bogor. Retrieved from http://download.portalgaruda.org/article.ph $p$ ?article $=181008 \& \mathrm{val}=6221 \&$ title $=$ KAJIAN \%20AKTIVITAS\%20ANTIOKSIDAN\%20D AN\%20ANTIMIKROBA\%20EKSTRAK\%20 BIJI,\%20\%20KULIT\%20BUAH $\% 20, \% 20 \mathrm{~B}$ ATANG\%20DAN\%20DAUN\%20TANAMA N\%20JARAK\%20PAGAR\% $20 \% 20 \% 20$ (Jat ropha\%20curcas $\% 20 \mathrm{~L}$.)

Sidabutar, E. A. (1999). Pengaruh jenis medium pertumbuhan mikroalga Chlorella sp. terhadap aktivitas senyawa pemacu pertumbuhan yang dihasilkan. Skripsi, Institut Pertanian Bogor, Studi Teknologi Hasil Pertanian. Retrieved from http://repository.ipb.ac.id/bitstream/handle/ 123456789/36455/C99eas.pdf?sequence= 1\&isAllowed $=y$

Tensiska, Marsetio \& Yudiastuti, O.N. (2007). Pengaruh jenis pelarut terhadap aktivitas antioksidan ekstrak kasar isoflavon dari ampas tahu. Hasil Penelitian, Universitas Padjajaran, Teknologi Industri Pangan. Retrieved from http://pustaka.unpad.ac.id/wpcontent/uploads/2009/05/pengaruh_jenis_p elarut.pdf 